\section{UNINTENTIONAL INJURIES IN SCHOOLCHILDREN IN FRANCE: CONTRIBUTION OF THREE SURVEYS AT 6, 10 AND 15 YEARS}

Anne-Laure Perrine, Louis-Marie Paget, Linda Lasbeur, Bertrand Thélot. Santé Publique France, Saint-Maurice, France

\subsection{6/injuryprev-2016-042156.455}

Background Unintentional injuries need to be better studied to be avoided, as they are responsible for 25,000 deaths per year in France, including one a day in children under 15 years old. One of the objectives of "school surveys" is to describe these injuries, the conditions of their occurrence, their severity, their consequences in terms of limitations and healthcare, and the factors associated with the injury.

Methods The same questionnaire on the occurrence of injuries was used in three nationally representative samples in France: 17,000 schoolchildren aged 5-6 years in 2012-2013, 7,000 schoolchildren aged 10-11 in 2004-2005, and 7,000 students aged 14-15 in 2008-2009. The data were weighted; descriptive and multivariate analyses were performed.

Results In the three months preceding the survey, 4\% of 5-6 year-olds, and $9 \%$ of $10-11$ and $14-15$ year-olds reported an injury. The proportion of traffic accidents was $10 \%$ at $14-15$ years, and only $4 \%$ at $10-11$ years and $2 \%$ at $5-6$ years. The proportion of fractures was similar among the three samples, representing between $20 \%$ and $24 \%$. Sprains increased with age: $8 \%$, $33 \%$ and $54 \%$. The head was the most affected part at 5-6 years (57\%) and lower limbs at 10-11 years and 14-15 years (41 and $48 \%$ ). Injuries were more frequent among boys in the three surveys, in middle class children, in children spending less time watching a screen, in children with a history of asthma or practicing a sport activity in the 14-15 years age group, and in overweight children in the 5-6 years age group. They were less frequent in 5-6 years and 10-11 years old children attending school in priority education zones.

Conclusions As all the children attend school in France, these results relate to all unintentional injuries of children of one age group. Further specific surveys on the most severe injuries are needed to define preventive actions.

\section{ROAD TRAFFIC INJURY PREVENTION AMONG SCHOOLCHILDREN, SPLIT AND DALMATIA COUNTY, CROATIA, 2015}

Ivana Bocina, Katja Matesan, Ingrid Tripkovic, Jasna Nincevic. Public Health Institute of Split and Dalmatia County, Croatia

\subsection{6/injuryprev-2016-042156.456}

Background All children in childhood are exposed to risk of road traffic injury (RTI). Insufficient road traffic orientation, education and other risk factors inherent to childhood make children vulnerable group. Routine mortality data obtained from the Croatian Bureau of Statistics for Split and Dalmatia County (SDC) showed 3 children aged 5-9 and 5 of them aged $10-14$ as victims of RTI deaths with mean annual mortality rate 3.5 and 3.3 per 100.000 respectively, during the observed period 2003-2013.

Objective Our project based on multidisciplinary approach is intended to improve knowledge on road traffic injury prevention (RTIP) and to increase road traffic skills among young schoolchildren (aged 6-10 years) in two elementary schools where two road traffic related deaths occurred (one at schoolyard and other nearby school bus station).
Results In accordance with the Third Road Safety Week celebration, Health Promotion and Disease Prevention Department in partnership with the Traffic Police Department, implemented pilot project on RTIP which included almost 300 schoolchildren. The project consisted of two workshops, educational and role playing one, designed by public health professionals and police officers. Pre and post questionnaire scores were compared to assess the effectiveness of the workshops. We used descriptive analysis. Results showed that children's knowledge of RTIP was insufficient. After implementing workshops, children improved knowledge of RTIP as well as their road traffic skills (increased competence in respecting traffic rules) and were able to take their own road safety measures responsibly (helmets, seat belts). Also they increased global awareness of injury prevention.

Conclusions Early and continuous education including road traffic skills improvement is essential aspect of RTIP among young schoolchildren. The formation of public health - police partnership can contribute to well RTIP which represents example of good practice.

\section{SETTING-UP AN EPIDEMIOLOGICAL MONITORING SYSTEM IN METROPOLITAN FRANCE: A CASE REVIEW OF DEATHS BY TRAUMA IN CHILDREN UNDER 15}

Linda Lasbeur, Bertrand Thélot. Santé Publique France, Saint-Maurice, France

\subsection{6/injuryprev-2016-042156.457}

Background In metropolitan France, trauma is the leading cause of death among children under 15 years: 450 annual deaths (source: Epidemiological Centre for Medical Causes of Death), with 220 deaths due to home and leisure injuries (HLI). These rough mortality data do not describe the circumstances of the trauma resulting in death.

Methods A feasibility study was conducted in 2009 in three regions covering one third of the population of metropolitan France. Through a case review, the main objective was to accurately describe how these HLI occurred, in order to determine their risk factors. Its secondary objectives were to test the feasibility and evaluate the opportunity of extending and/or scaling up the monitoring of these deaths.

Results Results of this feasibility study based on 76 HLI death certificates led to contact 219 medical certifiers, among whom 93\% filled the detailed questionnaire. The information collected allowed to characterise HLI and to identify risk factors: types and intensity of lack of supervision by adults (little child left alone at home, in the bath, parents asleep, etc.) in $75 \%$ of cases among children under 1 year and 57\% among 1-4 years children; lack of awareness (groundnut given to a toddler); parent's deny of risk (let a firearm accessible); the responsibility of dangerous products was mentioned in $43 \%$ among children under 15 years (for firearm, ring, crib bars, etc.) or misused by adults or children; the influence of inappropriate behaviour among teenagers in $70 \%$ of cases, etc.

Conclusions The conclusions of this feasibility survey are positive: data collection is effective and practicable with a high quality and exhaustiveness. They led in setting up a permanent survey at national scale on "Detailed analyses of deaths by trauma among children under 15", that started at end of 2015. The precise knowledge of the circumstances of these lethal traumas will be a basis to measure their avoidability and to prevent them. 